\title{
SENSITIVITY OF INTERNATIONAL ROUGHNESS INDEX TO DISTRESSES OF CEMENT CONCRETE ROAD SURFACES
}

The paper examined the sensitivity of International Roughness Index (IRI) to the local discontinuities (various distresses, joints, joint and surface defects, other road features, etc.) of the cement concrete (CC) pavements. About 5300 road records of total length $470 \mathrm{~km}$ from Long Term Pavement Performance (LTPP) program were processed. The raw profiles were separated into a random part and a distress part using the median filtering method. The median filter order was set to identify distresses of variable maximum width from 20 to $40 \mathrm{~cm}$, and minimal height, $3 \mathrm{~mm}$. About 26000 distresses were separated and their dimensions were identified. The raw longitudinal road profiles were compared with the separated pure random parts. The mean relative increase in IRI caused by distresses was $3.3 \%$ for maximum distress width $20 \mathrm{~cm}$, $6.6 \%(30 \mathrm{~cm})$, and $10.7 \%(40 \mathrm{~cm})$.

Keywords: Longitudinal road profile; road roughness; distress; crack; joint; slab; International Roughness Index; cement concrete (CC) pavement.

\section{Introduction}

The cement concrete pavements present $0.6 \%$ of the total length of road network in the Slovak Republic [1]. In some other countries the proportion of CC pavements is up to $20-30 \%$ of total road network. The typical part of CC pavement is a joint between slabs. The joint defects are major pavement distress form of rigid pavement. Distresses of CC pavements negatively affect ride comfort and ride safety. The four basic types of joints are used in practice - contraction (control) joints, isolation joints, construction joints, and warping joints [2]. Miller and Bellinger [3] divided the distresses typical for pavements with jointed CC surfaces into four groups: (a) cracking (corner breaks, transverse cracking, etc.), (b) joints deficiencies (joint seal damage, spalling of joints, etc.), (c) surface defects (map cracking, polished aggregate), (d) miscellaneous distresses (faulting of transverse joints and cracks, patch/patch deterioration, water bleeding, etc.). Joint deteriorations such as spalling, breaking, cracking, chipping, or fraying of the slab edges usually occur within $50 \mathrm{~mm}$ of joints [4].

International Roughness Index (IRI) is used in Pavement Management System (PMS) in the Slovak Republic to characterize the longitudinal road unevenness [5 - 8].

The research in the field of road distresses influence on the road unevenness indicators is predominantly focused on the influence of the vertical faults, i.e., vertical shifts between adjacent slabs, on the IRI statistics [9 - 13]. Only several papers [14 - 16] examined the influence of joint width, joint depth, joints spacing, or the road data processing on the IRI. The published results were predominantly oriented to the real road sections and the change of IRI with time. Mucka [17] analysed the influence of the artificial random profiles with superimposed joints with controlled dimension on the twenty one road unevenness indicators. The published results did not allow distinguishing between the contribution of the random profile part and the distress part to the total value of IRI.

Denotation 'distress' in this study means local discontinuities of various shapes and origins such as joints, joint deficiencies, surface defects, various distress types of $\mathrm{CC}$ pavements or other road features that were separated from a raw profile by the median filter. The median filter was set to separate distresses of variable maximum width from 20 to $40 \mathrm{~cm}$, and minimal height, $3 \mathrm{~mm}$.

The question to ask is whether distresses of CC pavements are an important factor affecting IRI that will influence the longerterm rehabilitation decision making.

The main objectives of this study are as follows:

Process the real $\mathrm{CC}$ road profiles by median filtering method and select a pure random part and a distress part from a raw profile;

\footnotetext{
* Peter Mucka

Institute of Materials and Machine Mechanics, Slovak Academy of Sciences, Bratislava, Slovakia

E-mail: ummsmuc@savba.sk
} 
- Identify every single distress and its own parameters and evaluate the statistics of all the distress parameters;

- Compare the IRI values calculated for a pure random profile with those calculated for a raw profile with distresses;

- Quantify the influence of distresses on the IRI;

- Evaluate the influence of the maximum width of the separated distresses on the results.

\section{International Roughness Index}

The IRI is essentially a computer-based virtual response-type system based on the response of a mathematical quarter-car vehicle model to the road profile. The IRI is based on simulation of the roughness response of a car travelling at $80 \mathrm{~km} / \mathrm{h}$ - it is the Reference Average Rectified Slope, which expresses a ratio of the accumulated suspension vertical motion of a vehicle, divided by the distance travelled during the test.

The IRI is a numeric that summarizes the roughness qualities impacting on vehicle response. The IRI is a dimensionless measure with units $(\mathrm{mm} / \mathrm{m})$ or $(\mathrm{in} / \mathrm{mi})$. The algorithm was proposed by Sayers et al. [18] and is also implemented in the prEN 13036-5 [19]. In Slovakia, the IRI is implemented in Technical specifications TP 04/2012 [5] and TP 05/2012 [20]. The road unevenness classification based on the IRI in Slovakia is shown in Table 1. PMS in Slovakia used $20 \mathrm{~m}$ interval for IRI estimation.

Limitations of the IRI to characterize the road unevenness were discussed in Mucka and Granlund [21] or Mucka [22] Calculation of the IRI and further specifications were published in Kovac et al. [4] and Decky and Kovac [23].

\section{Distress separation by median filtering method}

Common practice in road profiles processing is using the moving average filter. The median filter removes large vertical distresses in a longitudinal profile without or with limited affecting the random nature of the surrounding parts of the road profile. This feature is a great advantage when compared with the standard moving average filtering.
Median filtering approach [24] was applied to longitudinal raw profile $h_{\mathrm{RD}}$ to select a random part of profile $h_{\mathrm{R}}$ and a distress part $h_{\mathrm{D}}\left(h_{\mathrm{D}}=h_{\mathrm{RD}}-h_{\mathrm{R}}\right)$ of profile (Fig. 1). The distress dimensions - distress depth, $d_{\mathrm{D}}$, distress width, $w_{\mathrm{D}}$, and distance of successive distresses, $l_{\mathrm{D}}$, are schematically depicted in Fig. 1. It follows from the definition of the median filter that for the complete filtering of the non-random component including $\mathrm{m}$ discrete data, the $n \geq 2 m+1$ window length is needed [24]. The maximum distress width was considered to be $w_{\mathrm{DMAX}} \sim 20 \mathrm{~cm}$. The window length for median filter should be twice of the expected maximum distress width. Order of the median filter was selected to be as follows, $n=16(n \Delta l=40 \mathrm{~cm}, \Delta l$ is the sampling interval, $\Delta l=2.5 \mathrm{~cm}$ ). Distresses higher than the limit absolute value $\left|d_{\text {DLIM }}\right|=3 \mathrm{~mm}$ were only detected. The $d_{\text {DUNC }}$ quantity reflects the level of uncertainty of the distress residual random component.

The variable $\Delta_{\text {IRI }}$ quantifies the distress influence on the IRI and presents the difference between the IRI calculated for the raw profile with distresses $\left(\mathrm{RUI}_{\mathrm{RD}}\right)$ and for the separated pure random part $\left(\operatorname{IRI}_{\mathrm{R}}\right)$ of this profile as follows:

$\Delta_{\mathrm{IRI}}(\mathrm{mm} / \mathrm{m})=\mathrm{IRI}_{\mathrm{RD}}-\mathrm{IRI}_{\mathrm{R}}$
$\Delta_{\mathrm{IRI}}(\%)=100 \times \frac{\mathrm{IRI}_{\mathrm{RD}}-\mathrm{IRI}_{\mathrm{R}}}{\mathrm{IRI} \mathrm{I}_{\mathrm{R}}}$

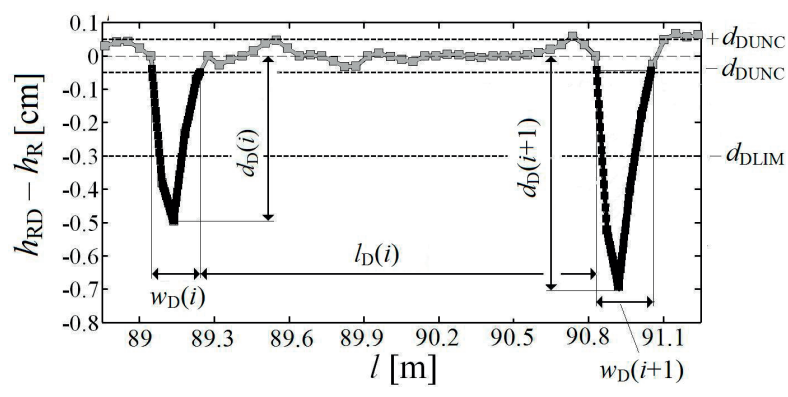

Fig. 1 Scheme of road distress characteristics obtained by median filtering method

The positive sign of variable $\Delta_{\text {IRI }}$ indicates that the value of IRI calculated for a raw profile is higher than that obtained for a separated random part. All computations were provided in Matlab $^{\circledR}$.

The road unevenness classification based on the IRI in Slovakia [5]

Table 1

\begin{tabular}{|c|c|c|c|}
\hline Road class & Motorways and expressways & $1^{\text {st }}$ and $2^{\text {nd }}$ class roads & $3^{\text {rd }}$ class roads and local highways \\
\hline 1 (very good) & $<1.90$ & $<1.90$ & $<3.30$ \\
\hline 2 (good) & $1.91-3.30$ & $1.91-3.30$ & $3.31-5.00$ \\
\hline 3 (fair) & $3.31-5.00$ & $3.31-5.00$ & $5.01-8.00$ \\
\hline 4 (poor) & $5.01-8.00$ & $5.01-10.00$ & $8.01-14.00$ \\
\hline 5 (very poor) & $>8.00$ & $>10.00$ & $>14.00$ \\
\hline \multicolumn{2}{|r}{} \\
\hline
\end{tabular}




\section{Results for road profile sample}

Figure 2 shows nine measurements of the left and right track elevation of the road test section \#180602 measured from March 1998 to September 2005. Section \#180602 is a jointed plain

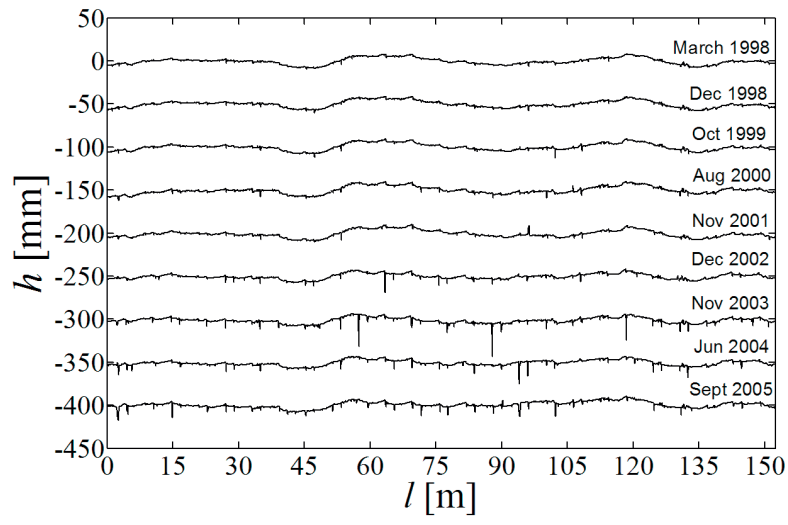

(a) concrete pavement (JPCP) with minimum preparation of original section. Partial depth patching other than at joint was provided on this section in April 2000 and June 2005 [25]. Two profilers provided the measurements - T-6600 profiler (K.J. Law) and MDR4086L3 profiler (International Cybernetics Corporation

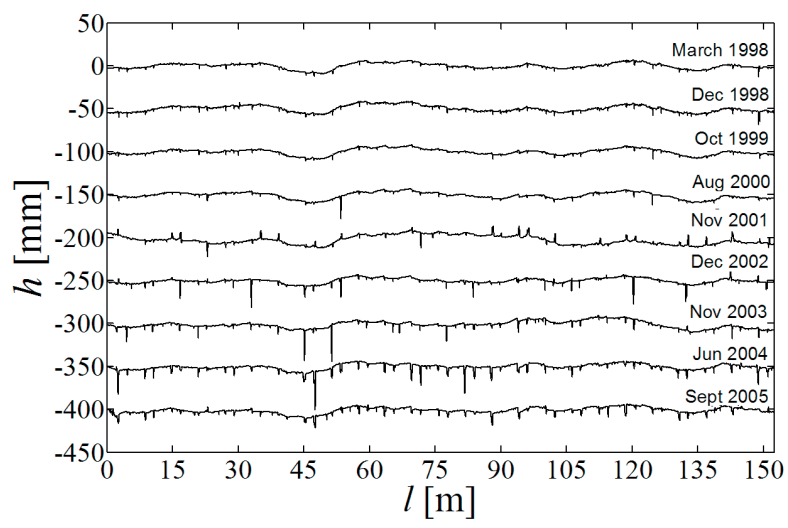

(b)

Fig. 2 Road elevation of the JPCP road test section \#180602 measured from 1998 to 2005 (shifted by 50 mm): (a) left track, (b) right track
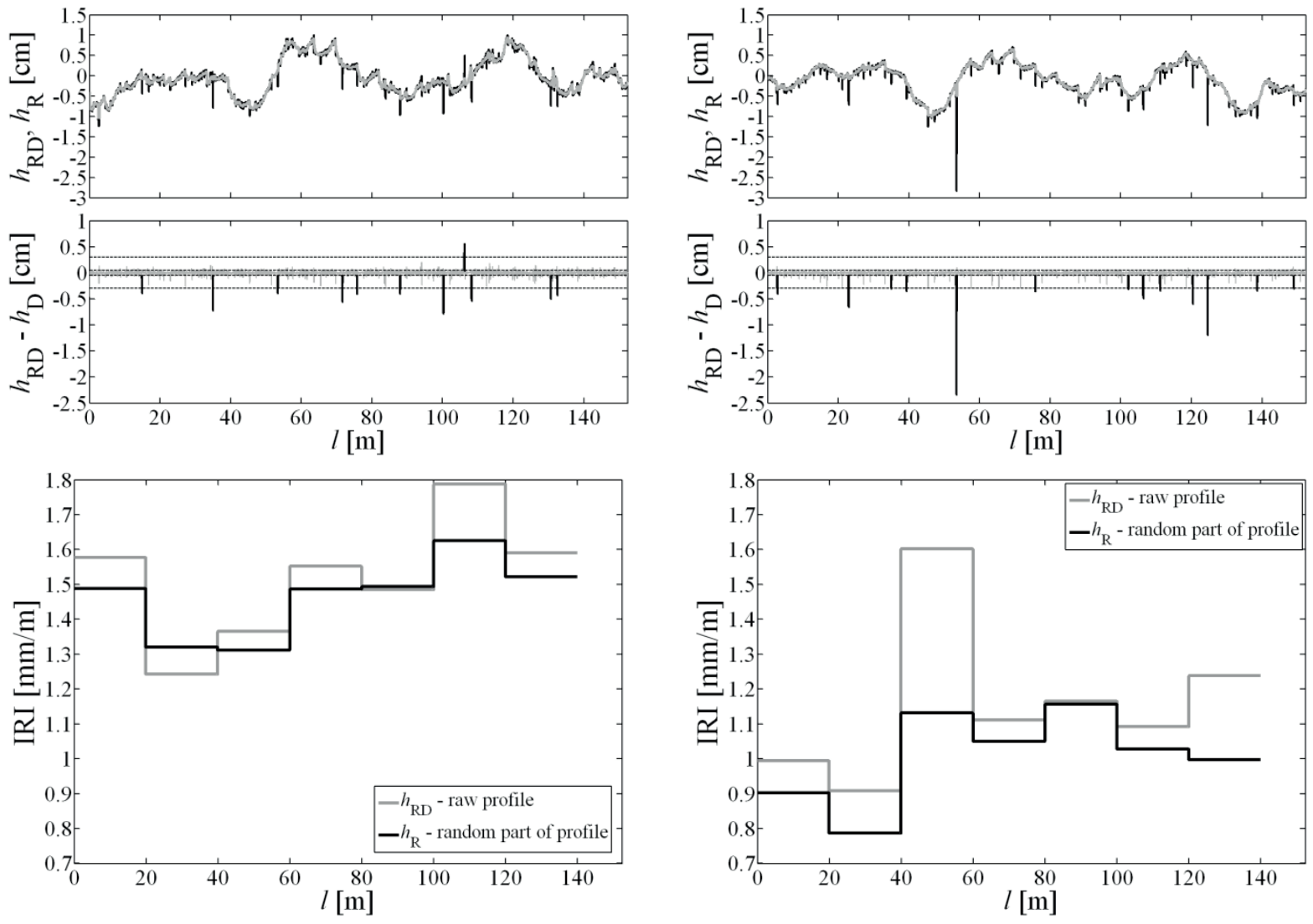

(a)

(b)

Fig. 3 Detection of road distresses (black line) by median filtering method $(n=16)$ for JPCC road section \#180602 measured in August 2000 and corresponding IRI values: (a) left track, (b) right track 


\begin{tabular}{|l|c|c|c|c|c|c|c|c|c|}
\hline \multirow{2}{*}{ Profiler } & \multirow{2}{*}{ Date } & \multicolumn{9}{|c|}{ Left track } & \multicolumn{4}{c|}{ Right track } \\
\cline { 3 - 11 } & & $N_{\mathrm{D}}$ & $\begin{array}{c}\text { mean }\left(\left|d_{\mathrm{D}}\right|\right) \\
(\mathrm{cm})\end{array}$ & $\begin{array}{c}\text { mean }\left(w_{\mathrm{D}}\right) \\
(\mathrm{cm})\end{array}$ & $\begin{array}{c}\text { mean }\left(l_{\mathrm{D}}\right) \\
(\mathrm{m})\end{array}$ & $N_{\mathrm{D}}$ & $\begin{array}{c}\text { mean }\left(\left|d_{\mathrm{D}}\right|\right) \\
(\mathrm{cm})\end{array}$ & $\begin{array}{c}\text { mean }\left(w_{\mathrm{D}}\right) \\
(\mathrm{cm})\end{array}$ & $\begin{array}{c}\text { mean }\left(l_{\mathrm{D}}\right) \\
(\mathrm{m})\end{array}$ \\
\hline K.J. Law & Mar 1998 & 5 & 0.40 & 10.8 & 27.8 & 20 & 0.43 & 12.5 & 7.6 \\
\hline K.J. Law & Dec 1998 & 7 & 0.37 & 10.9 & 20.5 & 41 & 0.47 & 11.1 & 3.6 \\
\hline K.J. Law & Oct 1999 & 10 & 0.45 & 11.5 & 14.3 & 15 & 0.47 & 11.9 & 10.3 \\
\hline K.J. Law & Aug 2000 & 11 & 0.52 & 12.9 & 11.6 & 13 & 0.62 & 13.0 & 12.1 \\
\hline K.J. Law & Nov 2001 & 7 & 0.50 & 10.8 & 19.2 & 27 & 0.52 & 16.6 & 5.6 \\
\hline ICC & Dec 2002 & 20 & 0.63 & 9.6 & 5.6 & 41 & 0.77 & 13.7 & 3.6 \\
\hline ICC & Nov 2003 & 37 & 0.83 & 12.2 & 4.0 & 47 & 0.75 & 14.1 & 3.1 \\
\hline ICC & Jun 2004 & 31 & 0.76 & 11.0 & 4.6 & 52 & 0.62 & 15.4 & 2.8 \\
\hline ICC & Sept 2005 & 35 & 0.64 & 12.4 & 4.1 & 48 & 0.45 & 14.7 & 3.1 \\
\hline
\end{tabular}

IRI for JPCP section \#180602

Table 3

\begin{tabular}{|c|c|c|c|c|c|c|c|c|c|c|c|}
\hline \multirow[b]{2}{*}{ Profiler } & \multirow[b]{2}{*}{ Date } & \multicolumn{5}{|c|}{ Left track } & \multicolumn{5}{|c|}{ Right track } \\
\hline & & $N_{\mathrm{D}}$ & $\begin{array}{c}\mathrm{IRI}_{\mathrm{R}} \\
(\mathrm{m} / \mathrm{km})\end{array}$ & $\begin{array}{c}\mathrm{IRI}_{\mathrm{RD}} \\
(\mathrm{m} / \mathrm{km})\end{array}$ & $\begin{array}{c}\Delta_{\mathrm{IRI}} \\
(\mathrm{m} / \mathrm{km})\end{array}$ & $\begin{array}{l}\Delta_{\mathrm{IRI}} \\
(\%)\end{array}$ & $N_{\mathrm{D}}$ & $\begin{array}{c}\mathrm{IRI}_{\mathrm{R}} \\
(\mathrm{m} / \mathrm{km})\end{array}$ & $\begin{array}{c}\mathrm{IRI}_{\mathrm{RD}} \\
(\mathrm{m} / \mathrm{km})\end{array}$ & $\begin{array}{c}\Delta_{\mathrm{IRI}} \\
(\mathrm{m} / \mathrm{km})\end{array}$ & $\begin{array}{l}\Delta_{\mathrm{IRI}} \\
(\%)\end{array}$ \\
\hline K.J. Law & Mar 1998 & 5 & 1.37 & 1.39 & 0.02 & 1.4 & 20 & 1.36 & 1.37 & 0.01 & 0.6 \\
\hline K.J. Law & Dec 1998 & 7 & 1.43 & 1.43 & 0 & 0.1 & 41 & 1.36 & 1.38 & 0.02 & 1.7 \\
\hline K.J. Law & Oct 1999 & 10 & 1.62 & 1.70 & 0.08 & 4.7 & 15 & 1.32 & 1.34 & 0.02 & 1.5 \\
\hline K.J. Law & Aug 2000 & 11 & 1.63 & 1.79 & 0.16 & 10 & 13 & 1.16 & 1.60 & 0.44 & 38.5 \\
\hline K.J. Law & Nov 2001 & 7 & 2.07 & 2.16 & 0.09 & 4.2 & 27 & 3.56 & 3.87 & 0.31 & 8.8 \\
\hline ICC & Dec 2002 & 20 & 1.67 & 1.76 & 0.09 & 5.8 & 41 & 1.61 & 2.63 & 1.02 & 62.7 \\
\hline ICC & Nov 2003 & 37 & 1.66 & 2.61 & 0.95 & 57.5 & 47 & 1.96 & 3.36 & 1.40 & 71.6 \\
\hline ICC & Jun 2004 & 31 & 1.58 & 2.15 & 0.57 & 36.4 & 52 & 4.70 & 6.27 & 1.57 & 33.2 \\
\hline ICC & Sept 2005 & 35 & 2.94 & 3.16 & 0.22 & 7.5 & 48 & 2.99 & 3.49 & 0.50 & 16.6 \\
\hline Mean (K.J. Law) & & & & & 0.07 & 4.1 & & & & 0.16 & 10.2 \\
\hline Mean (ICC) & & & & & 0.46 & 26.8 & & & & 1.12 & 46 \\
\hline
\end{tabular}

(ICC)). The ICC profiler with the laser sensor measures a higher roughness because it includes spikes that the K.J. Law profiler with the infrared sensor did not. The smaller footprint of the ICC profiler caused a jump in number of identified distresses.

Figure 3 presents the detection of road distresses by median filtering method [24] in analysed test section \#180602 measured in August 2000. The distress part of profile $\left(h_{\mathrm{D}}=h_{\mathrm{RD}}-h_{\mathrm{R}}\right)$ obtained by separation of the raw profile from the random part is shown in Fig. 3. The most common features presented in this profile are (a) spalling of transverse joints, (b) joint faulting, (c) transverse joint seal damage, (d) transverse crack, (e) asphalt concrete or CC patch, and (f) corner breaks [25]. The statistics of distresses in both tracks of profile \#180602 is shown in Table 2 . Value $N_{\mathrm{D}}$ presents the number of identified distresses.

Table 3 summarizes the IRI values for a pure random part of profile $\left(\mathrm{IRI}_{\mathrm{R}}\right)$ and for a raw profile with distresses $\left(\mathrm{IRI}_{\mathrm{RD}}\right)$ for nine measurements of JPCP road section \#180602. The IRI values for the raw profiles were slightly higher in comparison to the pure random part of profile. The mean percentage change $\Delta_{\mathrm{IRI}}$ [Eq. (1)] of IRI was $4.1 \% / 10.2 \%$ (left track/right track) for K.J. Law profiler and $10.2 \% / 46 \%$ for ICC profiler. Laser height sensors of ICC profiler have a circular footprint of about $1.5 \mathrm{~mm}$. The smaller footprint of the ICC profiler caused a jump in number of identified distresses.

Figure 4 shows the separation of a random part and a distress part of the raw profile by the median filter of order $n=24$ (length of window is $n \Delta l=60 \mathrm{~cm}, \Delta l=2.5 \mathrm{~cm}$ ) and by the moving average filter with the base length $60 \mathrm{~cm}$. Figure 4 illustrates a limited ability of moving average filter to separate the distress part. The differences between the moving average filter and the median filter are function of raw profile nature, distance of the successive distresses, the base length of the filters, etc. In some cases the ability or disability to remove distresses from a raw profile may be similar for both types of filters (see Fig. $4 \mathrm{~b}$ at $l=100.5 \mathrm{~m}$ ). 


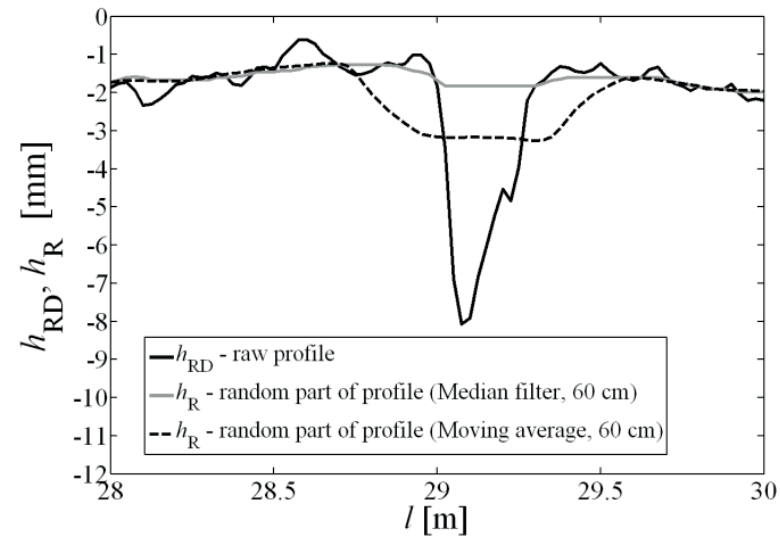

(a)

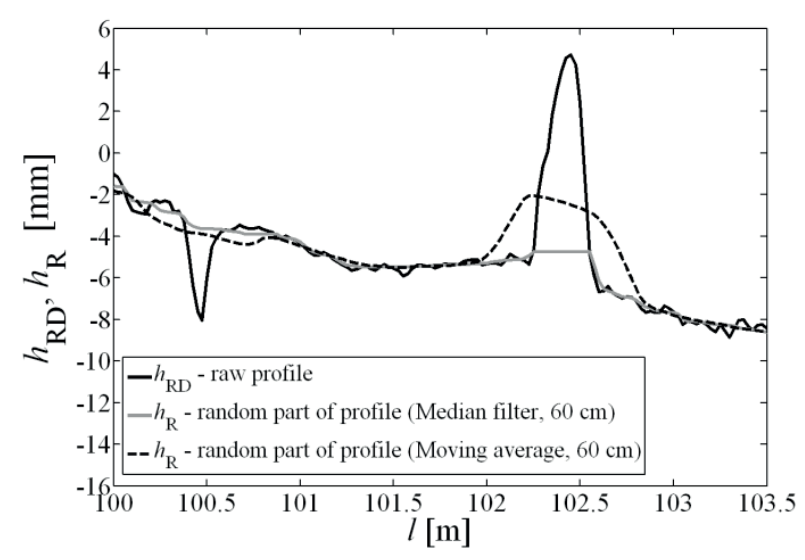

(b)

Fig. 4 Separation of the random part of the raw profile by the median filter $(n=24$, window length, $60 \mathrm{~cm})$ and by the moving average filter (base length = $60 \mathrm{~cm}$ ): (a) Example \# 1, (b) Example \#2

The IRI algorithm contains the pre-processing of a raw profile with a $25-\mathrm{cm}$ moving average [18]. The procedure for IRI calculation uses profile smoothing by the moving average filter to better represent the way in which tire of a vehicle envelops the ground. The pre-processing caused a lower sensitivity of IRI to the distresses. Further factor is the frequency response of the relative suspension velocity of the reference quarter car model intended for the IRI computation. This transfer function is most sensitive to the wavelengths $\sim 2 \mathrm{~m}$ with substantially lower gain corresponding to the wavelengths $<0.5 \mathrm{~m}$. The comprehensive analysis of the road profile spectral content influence on the IRI response was provided in Mucka and Granlund [21].

\section{Results for road profile database}

Road profile data from Specific Pavement Study SPS-2 "Strategic Study of Structural Factors for Rigid Pavements" related to the CC surfaces were analysed. This study is included in LTPP Program governed by Federal Highway Administration.

Table 4 presents the basic statistics of analysed sections and distress dimension for SPS-2 database. About 22300 road distresses were separated from 5266 road records. A total length of analysed record with at least one distress was $\sim 470 \mathrm{~km}$. Higher mean depth and width were detected in the right track.

Table 5 presents the influence of the median filter window length on the $\Delta_{\mathrm{IRI}}$ for SPS-2 database. Basic statistics of $\Delta_{\mathrm{IRI}}$ listed in Table 5 includes mean value, median, standard deviation (std), minimum ( $\mathrm{min}$ ), $95^{\text {th }}$ percentile (P95) and maximum (max). The mean value of the difference $\Delta_{\text {IRI }}$ increased with window length as follows: $\Delta_{\text {IRI }}=0.061 \mathrm{~mm} / \mathrm{m}\left(w_{\text {DMAX }}=20 \mathrm{~cm}\right), 0.118 \mathrm{~mm} / \mathrm{m}(30$ $\mathrm{cm})$, and $0.180 \mathrm{~mm} / \mathrm{m}(40 \mathrm{~cm})$.

Figure 5 shows the probability density function (PDF) of the difference $\Delta_{\text {IRI }}$ as a function of the median filter window length. The increase of the window length increased the ability to separate wider distresses from the raw profiles.

Statistics of the analysed road sections and separated distresses in SPS-2 database

Table 4

\begin{tabular}{|l|c|c|c|}
\hline & Left & Right & Total \\
\hline Profiles records analysed & 2633 & 2633 & 5266 \\
\hline Profiles records with detected distresses & 1480 & 1603 & 3083 \\
\hline Percentage of profiles with detected distresses (\%) & 56.2 & 60.9 & 58.6 \\
\hline Number of distresses & 9702 & 12602 & 22304 \\
\hline Total length of the analysed sections with at least one distress $(\mathrm{km})$ & 225.55 & 244.30 & 469.85 \\
\hline Number of distresses per km & 43.01 & 51.58 & 47.47 \\
\hline Mean distress depth $(\mathrm{cm})$ & 0.45 & 0.52 & 0.51 \\
\hline Standard deviation of distress depth (cm) & 0.48 & 0.46 & 0.47 \\
\hline Mean distress width (cm) & 9.8 & 10.0 & 9.9 \\
\hline Standard deviation of distress width $(\mathrm{cm})$ & 2.5 & 2.4 & 2.5 \\
\hline Mean distance of successive distresses $(\mathrm{m})$ & 25.3 & 23.4 & 24.3 \\
\hline Standard deviation distance of successive distresses $(\mathrm{m})$ & 23.2 & 22.4 & 22.8 \\
\hline
\end{tabular}


Statistics of difference $\Delta_{\text {IRI }}$ for SPS-2 database

Table 5

\begin{tabular}{|c|c|c|c|c|c|c|c|c|c|}
\hline \multirow[t]{2}{*}{ Median filter order, $n$} & \multirow[t]{2}{*}{ Track } & \multirow{2}{*}{$\frac{\begin{array}{c}\mathrm{IRI}_{\mathrm{R}} \\
(\mathrm{m} / \mathrm{km})\end{array}}{\text { mean }}$} & \multirow{2}{*}{$\begin{array}{c}\begin{array}{c}\mathrm{IRI}_{\mathrm{RD}} \\
(\mathrm{m} / \mathrm{km})\end{array} \\
\text { mean }\end{array}$} & \multicolumn{6}{|c|}{$\begin{array}{c}\Delta_{\mathrm{IRI}} \\
(\mathrm{m} / \mathrm{km})\end{array}$} \\
\hline & & & & mean & median & std & $\min$ & P95 & $\max$ \\
\hline \multirow{3}{*}{$\begin{array}{c}16 \\
\left(w_{\mathrm{DMAX}}=20 \mathrm{~cm}\right)\end{array}$} & Left & 1.74 & 1.80 & 0.055 & 0.042 & 0.09 & -0.16 & 0.14 & 1.71 \\
\hline & Right & 1.84 & 1.91 & 0.067 & 0.045 & 0.16 & -0.33 & 0.18 & 2.73 \\
\hline & Total & 1.79 & 1.85 & 0.061 & 0.043 & 0.13 & -0.33 & 0.15 & 2.73 \\
\hline \multirow{3}{*}{$\begin{array}{c}24 \\
\left(w_{\mathrm{DMAX}}=30 \mathrm{~cm}\right)\end{array}$} & Left & 1.69 & 1.80 & 0.107 & 0.090 & 0.13 & -0.15 & 0.22 & 2.85 \\
\hline & Right & 1.78 & 1.91 & 0.128 & 0.092 & 0.24 & -0.22 & 0.27 & 5.26 \\
\hline & Total & 1.73 & 1.85 & 0.118 & 0.091 & 0.20 & -0.22 & 0.24 & 5.26 \\
\hline \multirow{3}{*}{$\begin{array}{c}32 \\
\left(w_{\text {DMAX }}=40 \mathrm{~cm}\right)\end{array}$} & Left & 1.63 & 1.80 & 0.166 & 0.144 & 0.16 & -0.12 & 0.34 & 3.37 \\
\hline & Right & 1.71 & 1.91 & 0.194 & 0.149 & 0.32 & -0.10 & 0.38 & 6.37 \\
\hline & Total & 1.67 & 1.85 & 0.180 & 0.146 & 0.25 & -0.12 & 0.36 & 6.37 \\
\hline
\end{tabular}

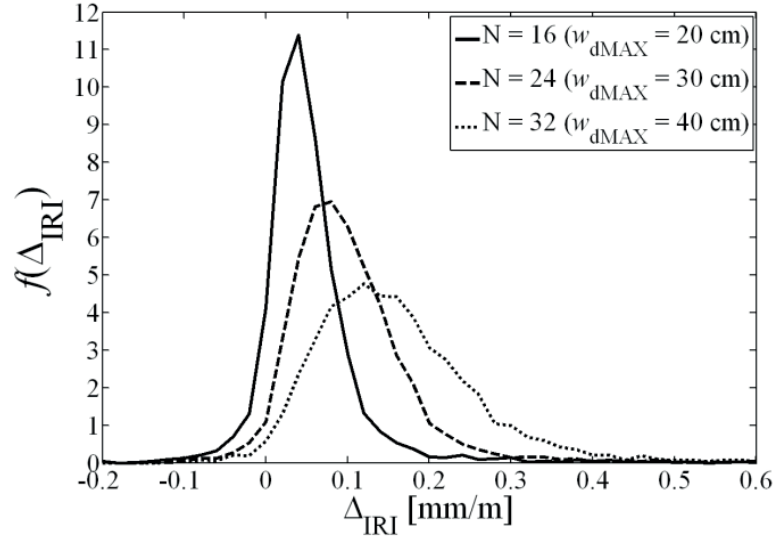

(a)

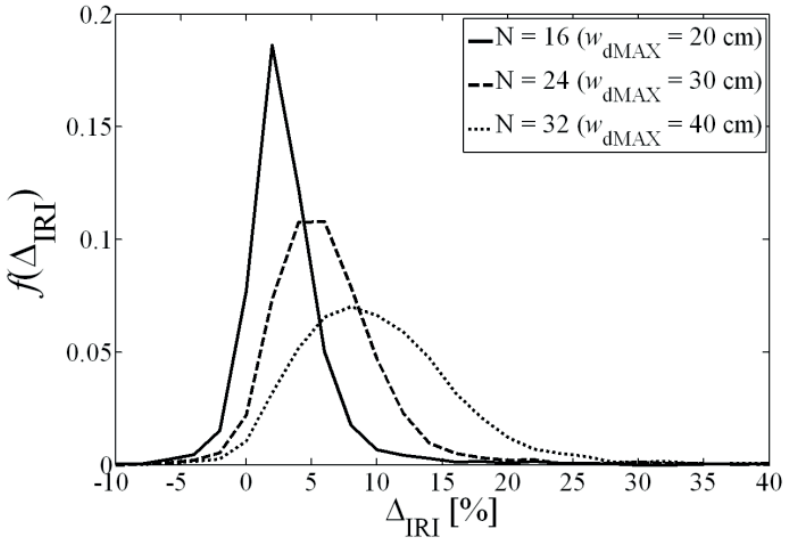

(b)

Fig 5 Probability density function of $\Delta_{I R I^{\circ}}$ (a) $\Delta_{I R I}(\mathrm{~mm} / \mathrm{m}),\left(\right.$ b) $\Delta_{I R I}(\%)$

\section{Conclusions}

The presented study brings some advantages in comparison to the previously published papers [9 - 16]. From the results, following findings may be stated:

1. The median filtering approach is the productive tool to separate the random and non-random parts of a longitudinal profile. The median filtering method allows quantifying the sensitivity of IRI to the distresses presence in a longitudinal profile. The median filter affects only slightly the nature of a random part as well as a distress part of a raw profile in comparison to the moving average filter.

2. The influence of the road distresses on IRI is function of the selected bandwidth applied on the raw profile. The mean percentage increase in IRI caused by distresses was calculated as follows: $3.3 \%\left(w_{\text {DMAX }}=20 \mathrm{~cm}\right), 6.6 \%(30 \mathrm{~cm})$, and $10.7 \%$ $(40 \mathrm{~cm})$. The mean increase in IRI in absolute values was
$\Delta_{\text {IRI }}=0.061 \mathrm{~mm} / \mathrm{m}\left(w_{\text {DMAX }}=20 \mathrm{~cm}\right), 0.118 \mathrm{~mm} / \mathrm{m}(30 \mathrm{~cm})$, and $0.180 \mathrm{~mm} / \mathrm{m}(40 \mathrm{~cm})$. Separated distresses of cement concrete pavements with maximum distress width about $40 \mathrm{~cm}$ have some influence on the IRI. The mean increase in IRI due to distresses of lower maximum width $(20 \mathrm{~cm}$ and $30 \mathrm{~cm}$ ) was relatively low.

3. Paper provides useful statistics of about 22300 distresses and other road features dimensions.

\section{Acknowledgements}

This work has been undertaken within the grant No. 2/0058/13 of the VEGA Grant Agency of Slovak Academy of Sciences. The help of the LTPP InfoPave Support Team is highly appreciated. 


\section{References}

[1] Review of road network data in the SR (in Slovak), Road databank : Slovak Road Administration, Bratislava, $2014,77 \mathrm{p.}$

[2] MCGHEE, K. H.: Design, Construction, and Maintenance of PCC Pavement Joints. NCHRP Synthesis of Highway Practice, vol. 211, 1995, Transportation Research Board, Washington, DC.

[3] MILlER, J. S., BELlingeR, W. Y.: Distress Identification Manual for the Long-Term Pavement Performance Program - $4^{\text {th }}$ revised ed., Report No. FHWA-RD-03-031, Office of Infrastructure Research and Development, Federal Highway Administration, McLean, Virginia, 2003.

[4] KOVAC, M., REMISOVA, E., CELKO, J., DECKY, M., DURCANSKA, D.: Diagnostic of Parameters of Roads Operational Capability (in Slovak). Zilina: EDIS : University of Zilina, 2012, ISBN 978-80-554-0568-1.

[5] TP 04/2012. Measurement and Evaluation of Road Roughness using Profilograph GE (in Slovak). Ministry of Transport, Construction and Regional Development of the Slovak Republic, Bratislava, SR, 2012, 20 p.

[6] CELKO, J., DECKY, M., KOMACKA, J., KOVAC, M.: Pavement Diagnosis as Integrant of the Pavement System, Communications - Scientific Letters of the University of Zilina, 2008, vol. 10, No. 2, pp. 44-49, ISSN 1335-4205.

[7] CELKO, J., KOVAC, M., DECKY, M.: Analysis of Selected Pavement Serviceability Parameters, Communications - Scientific Letters of the University of Zilina, 2011, vol. 13, No. 3, pp. 56-62. ISSN 1335-4205.

[8] MIKOLAJ, J., REMEK, L., PEPUCHA, L.: Overview of the Road Network Management System, Communications - Scientific Letters of the University of Zilina, 2014, vol. 16, No. 4, pp. 53-57. ISSN 1335-4205.

[9] KHAZANOVICH, L., DARTER, M. I., BARTLETT, R. J., MCPEAK, T.: Common Characteristics of Good and Poorly Performing PCC Pavements. Report No. FHWA-RD-97-131, Federal Highway Administration, U. S. Department of Transportation, Washington, DC, 1998.

[10] PERERA, R. W., BYRUM, C., KOHN, S. D.: Investigation of Development of Pavement Roughness. Report No. FHWA-RD-97-147, Federal Highway Administration, U.S. Department of Transportation, Washington, DC, 1998.

[11] SELEZNEVA, O., JIANG, J., TAYABJI, S. D.: Preliminary Evaluation and Analysis of LTPP Faulting Data. Report No. FHWA-RD00-076, Federal Highway Administration, U.S. Department of Transportation, Washington, DC, 2000.

[12] BYRUM, C. R., PERERA, R. W.: The Effect of Faulting on IRI Values for Jointed Concrete Pavements. Proc. of $8^{\text {th }}$ Intern. Conference on Concrete Pavements: Innovations for Concrete Pavement: Technology Transfer for the Next Generation, Colorado Springs, CO, 14-18 August 2005, Colorado: International Society for Concrete Pavements, vol. 2, 2005, pp. 755-770.

[13] LIU, C., WANG, Z.: Influence of Joints on Ride Quality and Roughness Index. Road Materials and Pavement Design, 2008, vol. 9, No. 1, pp. 111-121, ISSN 1468-0629.

[14] MORIAN, D. A., GIBSON, S. D., EPPS, J. A.: Concrete Pavement Maintenance Treatment Performance Review: SPS-4 5-year Data Analysis. Report No. FHWA-RD-97-155, Federal Highway Administration, U.S. Department of Transportation, Washington, DC, 1998.

[15] BYRUM, C. R.: Analysis by High-speed Profile of Jointed Concrete Pavement Slab Curvature. Transportation Research Record, 1730, Transportation Research Board, Washington, DC, 2000.

[16] HALL, K. T., CROVETTI, J. A.: LTPP Data Analysis: Relative Performance of Jointed Plain Concrete Pavement with Sealed and Unsealed Joints. NCHRP Web Document 32, National Cooperative Highway Research Program, Transportation Research Board, Washington, DC, 2000.

[17] MUCKA, P.: Sensitivity of Road Unevenness Indicators to Distresses of Composite Pavements, Intern. J. of Pavement Research and Technology, 2015, vol. 8, No. 2, pp. 72-84. ISSN 1997-1400.

[18] SAYERS, M. W., GILlESPIE, T. D., PATERSON, W. D. O.: Guidelines for Conducting and Calibrating Road Roughness Measurements. Technical Paper No. 46, The World Bank, Washington, DC, 1986.

[19] prEN 13036-5: 2015. Road and Airfield Surface Characteristics - Test Methods. Part 5: Determination of longitudinal unevenness indices. European Committee for Standardization (CEN), Brussels.

[20] TP 05/2012. The Methodology for the use of HDM-4 in Terms of SROV (in Slovak). Ministry of Transport, Construction and Regional Development of the Slovak Republic, Department for Road Traffic and Roads, Bratislava, SR, 2012, 76 p.

[21] MUCKA, P., GRANLUND, J.: Is the Road Quality Still Better? J. of Transportation Engineering - ASCE, 2012, vol. 138, No. 12, pp. 1520-1529. ISSN 0733-947X.

[22] MUCKA, P.: Correlation among Road Unevenness Indicators and Vehicle Vibration Response, J. of Transportation Engineering ASCE, 2013, vol. 139, No. 8, pp. 771-786. ISSN 0733-947X.

[23] DECKY, M., KOVAC, M.: The Longitudinal Road Evenness of the Road Network (in Slovak), EDIS : University of Zilina, 2014, ISBN 978-80-554-0925-2. 


\section{COMMNICOIIONS}

[24] KROPAC, O., MUCKA, P.: Specification of Obstacles in the Longitudinal Road Profile by Median Filtering. J. of Transportation Engineering - ASCE, 2011, vol. 137, No. 3, pp. 214-226, ISSN 0733-947X.

[25] LTPP InfoPave [online]. 2014. Federal Highway Administration, US Department of Transportation, Available from: www. infopave.com [Accessed 20 February 2014]. 